\title{
Subject Matter and Pre-Requisites for Protection of Non-Conventional Trademark
}

\author{
Aishwarya Vatsa*
}

\section{Abstract}

We have been gifted with senses other than our eyes, which the non-conventional trademarks aim to employ and have thus gained popularity. These marks have gradually acquired acceptance and have been included under the ambit of trademarks in various countries of the world. Trademark law aims at facilitating profit and strengthening the identity of a business. Nonconventional marks too, perform the same function. The United States has taken a similar approach and has thus provided protection to various such non-conventional marks. India, on the other hand, is yet to take a similar approach. The present law in India disallows the registration of such marks, proving to be a hindrance in their registration, rather than a facilitator. This paper discusses the concept and definition of non-conventional marks, its subject matter and the prerequisites for its registration. By comparing the different approaches to non-conventional trademarks and the procedure for their registration across different countries, this paper aims at suggesting a model suitable for adoption in India.

Keywords: Graphical representation, Indian Trademarks Act, 1999, International Classification of the Figurative Elements of Marks, 2018, TRIPS Agreement, 1995

\footnotetext{
LLM, Hidayatullah National Law University, Raipur, India, aishwaryavts22@gmail.com
} 


\section{Introduction}

Traditional examples of trademarks are confined primarily to words, symbols, designs, or a combination of these. These categories are similar throughout the world, even if the nature of the protection accorded to them may differ from country to country. The definition of non-traditional trademarks is extremely wide. Generally, they are considered as a new type of a trademark which does not belong to a pre-existing, already known and regulated list of trademarks. ${ }^{1}$ The Paris Convention for the Protection of Industrial Property does not offer a definition of nontraditional trademarks stating only that "the conditions for the filing and registration of trademarks shall be determined in each country of the Union by its domestic legislation." 2 The Madrid Agreement and the Protocol relating to the Madrid Agreement concerning the International Registration of Marks and the Agreement concerning the International Registration of Marks ${ }^{3}$ are also silent on the definition of a trademark and do not specify the scope of a mark.

The Agreement on Trade Related Aspects of Intellectual Property Rights, provides for a minimum standard of protection, which has to be ensured by the states that are party to it. Members are provided the freedom for the implementation of the requisite laws. ${ }^{4}$ This flexibility is provided by the TRIPS Agreement, 1995, through several international treaties, such as the Paris Convention, Madrid System, Trademark Law Treaty, Singapore Law Treaty etc. which try to achieve some degree of standardization and uniformity. The only international treaty that directly and expressly excludes nontraditional marks from the trademark protection, is the Trademark

1UlgaMurgolova, Non Traditional Trademarks, Uppasala University, (2017), http://www.diva-

portal.org/smash/get/diva2:1109691/FULLTEXT01.pdf (last accessed on 16 September 2018)

2 Paris Convention for the Protection of Industrial Property, Art. 6(1) Sept. $28,1979$.

${ }^{3}$ Sept. 28, 1979.

4The Agreement on Trade-Related Aspects of Intellectual Property Rights, Art. 1, Jan. 1, 1995. 
Law Treaty which was signed in $1994 .{ }^{5}$ However, the International Classification of the Figurative Elements of Marks (Vienna Classification) provides a list of non-traditional trademarks which may be registered including sound marks ${ }^{6}$ and colour marks. ${ }^{7}$

Different countries have different approaches to protection of trademarks. However, it is also true that the protection of nonconventional trademarks is more difficult than traditional trademarks. ${ }^{8}$ Traditional trademarks have been in use and are also widely accepted by the market. The law also provides extensive protection to traditional trademarks. Non-traditional trademarks on the other hand, are a comparatively recent development within the field of intellectual property rights. The law regarding its protection, therefore, is comparatively nascent and still in its formative years. The general principles of protection of such marks can however be deciphered mostly from cases and interpretations of certain statutes.

Many countries, like India, do not have explicit laws providing for their protection. The Trademark Act, 1999, for instance, is silent on the matter. In such countries the protection is guided by trademark regulations and individual cases decided by the Courts. The general requisites for protection of conventional and nonconventional trademarks have been discussed in Article 15 of the TRIPS Agreement. These prerequisites include acquired or inherent distinctiveness, graphical representation or visual perceptibility. ${ }^{9}$ However, its compliance is not made mandatory, as the word may is used. ${ }^{10}$ It is also mentioned that the nature of goods should not

5 Trademark Law Treaty, Art. 2(1)(b), Oct. 27, 1994.

6 International Classification of the Figurative Elements of Marks, Category 24.17.10 (Musical symbols), Jan. 1, 2018

7 International Classification of the Figurative Elements of Marks, Category 29.1 (Colours), Jan. 1, 2018.

${ }^{8}$ L. Kenneth Port, On Nontraditional Trademarks, 38(1) N. Ky. L. Rev.1, (2012).

${ }^{9}$ The Agreement on Trade-Related Aspects of Intellectual Property Rights, Art-15(1), Jan. 1, 1995.

10 The Agreement on Trade-Related Aspects of Intellectual Property Rights, Art-15(3), Jan. 1, 1995. 
be an obstacle to its protection. The mode of implementation of these minimum standards of protection varies from country to country. The acceptability of a non conventional trademark in a country may not ensure its acceptability in another. The same applies to rules of graphical representability. For example, a color registered as a trademark may not be fit for registration in another country, considering that the specific color may have religious significance in the said country. ${ }^{11}$

\section{Non-Conventional Trademark}

A trademark is a sign that serves to distinguish and individualize goods or services. In other words, it serves as a source indicator an indication that a certain product is manufactured or processed by a certain manufacturer, thereby assuring the buyer of its origin and quality. The Trademark Act, 1999 defines such trademark as, "a mark capable of being represented graphically and which is capable of distinguishing the goods or services of one person from those of others and may include shape of goods, their packaging and combination of colors." 12

The word mark in the definition has been accorded an inclusive definition, including "a device, brand, heading, label, ticket, name, signature, word, letter, numeral, shape of goods, packaging or combination of colors or any combination thereof." 13 However, the ambit of a trademark may not be limited to the above mentioned definition. This is where the concepts of conventional and nonconventional trademarks arise. Conventional trademarks are those which have been in use generally, such as words, devices, headings etc. For example, the word Nike. The sign used is that of a tick mark and the title used therein is just do it. Such marks have been in use since a long time and the law agrees to legally recognize them, provided certain criteria such as those of distinctiveness,

11 Neha Mishra,Registration of Non-Traditional Trademarks, 13(1) JIPR,43, (2008).

$12 \S 2(\mathrm{zb})$, The Trademarks Act, 1999, Act No. 47 of 1999, Acts of Parliament, 1999.

13 §2(m), The Trademarks Act, 1999, No. 47 of 1999, Acts of Parliament, 1999. 
whether acquired or inherent, graphical representation, and other qualifications as mentioned in Sections 9 and 11 of the Trademarks Act are fulfilled.

However, with the passage of time and development in the economy, the marketplace has grown to become increasingly competitive. Hence, trademarks began engaging senses other than sight, such as sound, smell, taste, motion etc. Businesses explored newer avenues in relation to these senses to create a distinctiveness for the brand, to enable the consumer to associate more with the brand and the mark. The effectiveness of any trademark depends upon its ability to create an impact on its users. If the characterization or representation of a product is unique, it would naturally appeal to the people and senses in a very significant manner. ${ }^{14}$ Different trademarks are coming up every day which engage different senses of human beings, such as a musical note to associate with the brand, ${ }^{15}$ floral scent for sewing thread, ${ }^{16}$ a landmark building for a hotel (TM Reg. No. 3386351), etc., are all examples of trademarks which fall outside of the traditional definition of trademarks.

The scope of non-conventional trademarks is extremely wide and is not limited to works, marks or devices, as is generally the case in relation to a traditional trademark. This has been made possible by the advent of numerous such marks and broad definitions provided by different international agreements such as the TRIPS Agreement. The definition provided for a trademark, by the agreement, only provides minimum criteria for its registration. As per the agreement, "Any sign, or any combination of signs, capable of distinguishing the goods or services of one undertaking from

${ }^{14}$ ArkaMajumdar \&Sunandam Majumdar, Requirement of Graphical Representability for Non Conventional Trademarks, 11 JIPR, 313 (2006).

15 Controller General of Patents Design and Trademarks, Yahoo's Yodel, (No.

85870007),

2013.http://ipindiaonline.gov.in/tmrpublicsearch/frmmain.aspx\#, (last accessed on 16 September 2018)

${ }^{16}$ Re Celia Clarks, 17 USPQ 2d 1238(TTAB 1990) 
those of other undertakings, shall be capable of constituting a trademark." 17

\section{Subject Matter of Non-Conventional Trademark}

Any trademark which is outside the purview of conventional marks are categorized as non-conventional trademarks, and hence, its subject matter encompasses various types of trademarks. The different non-conventional trademarks that will be discussed hereinafter are - shape marks, sound/aural marks, smell/olfactory marks, taste marks, color marks, motion marks, holograms, touch marks and image marks for landmarks. These are the marks constituting the subject matter of non-conventional marks that are used and registered worldwide. Its scope is ever expanding. The functions of a trademark are no longer perceived by businesses and economists as limited to the signification of origin and the identification of the goods or services to which the mark is attached, but also to indicate the quality of the goods and promote them in the minds of consumers. ${ }^{18}$

\subsection{Color Marks}

A color or a combination of colors which is distinctive, is capable of being registered as a trademark. The precondition, however, is that the said color or combination of colors, should be distinctive and capable of differentiating the goods, by serving as a badge of origin. ${ }^{19}$ A sign consisting of a color as such may have an acquired distinctive character. It should be clear, self contained, intelligible, easily identifiable and capable of being graphically represented. Although a mere reproduction of the color on paper is not enough, but a reference to a suitable code for the color may be, depending on the case. A color when employed as a trademark can be registered provided it fulfills certain conditions. It is necessary that

\section{Supra note 8 .}

18Sarwar Choudhary, Scope of Trademark Protection ,Faculty of Law, University of Lund Publications, http:/ /lup.lub.lu.se/luur/download?func=downloadFile\&recordOId=15 55315\&fileOId=1563618, (2007) (last accessed on 15 September 2018)

${ }^{19}$ Elizabeth Verkey, Intellectual Property(1st edition. 2015). 
it is capable of being a sign/mark, of being graphically represented and of being a distinguishing factor. ${ }^{20}$

A color trademark can play a very significant role in facilitating consumer identification, as not all categories of consumers are literate and can identify with the work, device or heading used for the mark. In relation to such consumers, if the mark has a distinctive color that has been used for a long time, it can serve as a distinguishing factor in itself. For example, the color purple that is used for Cadbury Dairymilk, has acquired a distinctiveness in our country. Many consumers identify the color in relation to the said brand of chocolate. Due to its popularity and capability of being associated with a particular brand of chocolate, the said color requires protection under trademark law. This is necessary in order to prohibit other brands from copying the color of the chocolate, in order to create a deceptive similarity, thereby misleading the public. ${ }^{21}$ Although they were unable to register the general color purple, they were successful in registering a specific shade of purple as a trade mark, when used on the packaging for blocked and boxed chocolates.22 There is, however, a general objection to the recognition of colors as the subject of trademarks given their limited palette. It is argued that it is not a wise policy to foster further limitation by permitting trademark registrants to deplete the reservoir. This is better known as the color depletion theory. ${ }^{23}$

\subsection{Sound Marks}

Sound or Aural trademarks are trademarks wherein the identifying function of the mark is accomplished by an audio tune. The source is indicated by a musical note, an audio clip or a jingle. Sound marks have been registered and protected in numerous cases as

\footnotetext{
${ }^{20}$ LibertelGroep BV v. Benelux-Merkenbureau, (2003) E.C.R I-3793, (Europe)

${ }^{21}$ Cadbury v. Nestle, (2017) E.W.C.A. Civ. 358, (United Kingdom).

${ }^{22}$ Kritarth Pandey, Non Conventional Trade Mark: A Legal Analysis, Social Science Research Network, (Feb. 20, 2014) https:// papers.ssrn.com/sol3/papers.cfm?abstract_id=2399286 (last accessed on 15 September 2017).

23 Campbell Soup Co. v. Armour and Co, (1949), 338 U.S. 847 (United States of America)
} 
compared to other non-conventional trademarks. Multiple sound marks have been registered in India, where the registration of other non conventional marks is fewer. The first sound mark to be registered in India was Yahoo yodel. Many other sound marks such as ICICI Bank sound mark, Allianz mark etc. have been registered in India.

The registration of the mark depends on its capability of being represented graphically. There have been several instances wherein, onomatopoeia and written description of sounds have been rejected, ${ }^{24}$ and the stave and clef method accepted. This method requires that the relevant sound mark be depicted in the form of accurate musical notes in order to be registered as a trademark. In India, the representation of a sound mark must be clear, precise, self-contained, easily accessible, intelligible, durable and objective in order to receive trademark protection. Additionally, the application should clearly state it is a sound mark which is also described in musical notes. ${ }^{25}$

\subsection{Smell Marks}

A scent may be registered as a trade mark. A scent trademark is a distinctive smell used in relation to goods or services, to distinguish them from the goods or services of other traders. In order to constitute a trademark, it should be associated with the product even if it does not serve a functional purpose. The smell must be unique - it must be a feature added by the applicant and should not be an inherent attribute of the mark itself. This was also held in Clarks case, wherein smell mark was granted for the scent of plumeria blossoms on sewing threads. ${ }^{26}$ However, its representation is quite tricky. The protection is given only when the applicant is able to represent the mark. Such representation must be precise and distinct. The chemical formula in itself does not

24 Shield Mark BV v. Joost Kist h.o.d.nMemex, (2004), Case-C-283/01, R.P.C 17.

25 Draft Manual for Trade Mark Practice and Procedure of India, Ministry of Trade and Commerce of India (2015).

26 Supra note 15. 
constitute a sufficient representation, neither is just an odour sample. ${ }^{27}$

\subsection{Shape Marks}

Shape marks are marks where the source indication of the product is done via the shape of the product, which acts as the source indicator, provided it does not serve a functional purpose. The secondary meaning which is acquired by the mark should be both conceptual and functional. The Trademarks Act, 1999 prohibits registration of a shape which results from the nature of the product itself. It further prohibits registration of shapes which are necessary to obtain a technical result or functionality, or such shapes which give substantial value to the goods. ${ }^{28}$ Shape marks are recognized as trademarks in many countries, including India, provided the graphical representation is clear and serves no functional purpose. In SwizzelMalto Ltd.'s application ${ }^{29}$ where an application of registration was made for a $3 \mathrm{D}$ heart confectionary, the registration was granted after the application was modified and the graphical representation was made adequate.

The Indian courts have recognized shape marks in cases like Gorbatschow Vodka KG v. John Distilleries Limited, ${ }^{30}$ wherein, the Mumbai High Court recognized the uniqueness of the shape of the product bottle and subsequently prohibited the defendant from using a bottle shape that was identical or deceptively similar to that used by the plaintiff. Similarly in Zippo Manufacturing Company $v$ Anil Moolchandani, ${ }^{31}$ the shape of 3D lighters was recognized and consequently, a decree for permanent injunction was passed against the defendant from selling, distributing or marketing lighters under the ZIPPO mark or with a 3D shape that was

27 Ralf Sieckmann v. Deutsches Patent and Markenamt, (2002) A.1.1E.R(D) 185.

$28 \S 9(3)$, The Trademarks Act, 1999, No. 47 of 1999, Acts of Parliament, 1999.

${ }^{29}$ SwizzelMalto Ltd. Application(No.2) (2000) E.T.M.R 58.

${ }^{30}$ Gorbatschow Vodka KG v. John Distilleries Limited, (2010), SUIT NO.3046, Bom. H.C.

31Zippo Manufacturing Company v/ Anil Moolchandani (2006) CS(OS) 1355. 
identical or similar to that of a Zippo lighter, as depicted on its registration certificate. The mark and its protection will be discussed in detail in the subsequent section on Shape Marks.

\subsection{Image Marks}

Image trademarks over buildings also come under the ambit of non-conventional trademarks. In case the building satisfies the dual test of graphical representation, along with the capability of functioning as an indication of source, there is no reason why they should be disallowed protection. The concept of buildings as trademarks have been recognized in certain cases in India as well as abroad. The only building to be registered in India as a trademark is the Taj Palace Hotel in Mumbai. Trademark registrations have been sought and in many instances obtained for landmarks used in connection with various goods and services, including movie theaters, ${ }^{32}$ museums and historic houses, ${ }^{33}$ sports stadiums, ${ }^{34}$ etc. As regarding the criteria for its registration, the United States Patent and Trademark Office, (USPTO) takes the position that "the three-dimensional configuration of a building is able to be registered only if it is used in such a way that it is or could be perceived as a mark." 35

\subsection{Taste Marks}

If a mark is capable of serving as an indicator on the basis of the taste of its product, it can be registered as a trademark. It is one of the least recognized conventional trademarks, with no instance of its registration in India. The functionality principle is a significant hurdle for any party seeking to protect a particular flavor or taste as a taste mark. The U.S T.M Trial and Appeal Board denied a

32 Mann's Chinese Theater, Trademark Exam. Dep't of the United States Pat. \& Tm. Office, July 27, 1999, Reg. No. 2,263,968.

33 Rock \& Roll Hall of Fame, Cleveland, Ohio, Trademark Exam. Dep't of the United States Pat. \& Tm. Office, November 11, 1997, Reg. No. 2,112,793 34 Yankee Stadium, Trademark Exam. Dep't of the United States Pat. \& Tm. Office, filed June 17, 1998 (façade, Serial No. 75/505,795; aerial view, Serial No. 75/505,796)

35 Patent And Trademark Office, U.S. Dep't Of Commerce, Trademark Manual Of Examining Procedure, § 1301.02(c) (Aug. 1997) 
pharmaceutical company over the orange flavor of its pills, as it can serve a functional purpose of masking the bad taste of the medicine. ${ }^{36}$ However, the distinct flavor of a rainbow cone has been registered, as it is a combination of five fine flavors of ice cream, with a unique taste. ${ }^{37}$ Functionality is generally an obstacle to the recognition of the mark. However where it can be proved that the mark has acquired a distinctiveness, such marks can be protected.

\subsection{Touch Marks}

Similar to taste marks, touch marks are seldom recognized and protected as functionality bars such marks in the majority of its use. However, in cases where the use of a mark to engage the sense of touch as a source indicator exists and it has acquired a distinctiveness for itself, the mark can be protected.

\subsection{Motion Marks}

Motion marks are animated marks - marks constituting a moving or animated clip in connection with the mark involved. Its registration is dependent upon the description presented in the application of the various components or elements of the trademarks and their interaction with each other explained in a sequence of steps. The mark should be distinctive and nonfunctional. They are recognized in the U.S as well as in the E.U. In Canada, the registration is dependent over its registration in a foreign country. Some examples would be the lion roar of MGM pictures,(Canadian Trademarks Details-TMA828890) the motion mark of Columbia pictures, Dreamworks (United States Patent and Trademark Office Registration no. 5020252) etc. They are recognized in various cases, however, there has been no stance of registration of a motion mark in India.

\subsection{Holograms}

Holograms were initially used for security purposes on debit and credit cards for authenticity, as its depiction and replication are comparatively difficult. Over time, there have been instances of using Holograms as marks, and is even recognized in the U.S. It is

\footnotetext{
36 Re N.V. Organon, (2006) 79 U.S.P.Q.2d 1639. (United States of America) 37 U.S T.M Registration No-1,623,869
} 
registered, provided it fulfills its criteria of non-functionality and the mark should be distinctive enough to be used by a business, to uniquely identify itself and its products and services to consumers. ${ }^{38}$ However, such marks are not recognized in India, yet.

\section{Functional Definition of Trademark}

The definition of trademarks as provided in various national legislations and international treaties is open-ended. The definitions are not inclusive and only set out certain basic requirements for a trademark. The Lanham (Trademark) Act, defines a trademark as;

including any word, name, symbol, or device, or any combination thereof used by a person, or which a person has a bona fide intention to use in commerce and applies to register on the principal register established by this chapter, to identify and distinguish his or her goods, including a unique product, from those manufactured or sold by others and to indicate the source of the goods, even if that source is unknown. ${ }^{39}$

A similar definition is provided by the E.U Trademarks Directive, which defines trademarks as a mark which is capable of distinguishing goods or services of one undertaking from another, and capable of being represented. The definition also recognizes non-conventional trademarks such as color, shape of goods and sounds. ${ }^{40}$ The Indian Trademarks Act, 1999 also recognizes a similar definition as is shown above. Thus, based on the national legislations, it is concluded that the definition remains more or less open ended in essence. Registration is provided with ease, provided certain criteria are fulfilled.

When it comes to International agreements, the approach is similar. Trademarks are "any sign, or any combination of signs, capable of distinguishing the goods or services of one undertaking from those

38Pandey, supra Note 23.

39 The Lanham(Trademark) Act, 1999, 15 U.S.C §1127.

40Directive(EU) 2015/2436 of the European Parliament and of the Council, Art. 2, (2015). 
of other undertakings, shall be capable of constituting a trademark." 41 Furthermore, the article describes what constitutes a sign, and include non-conventional marks such as colors, or any combination thereof. The requirement being that, the mark is visually perceptible. Thus, nonconventional marks are not excluded from the ambit of trademarks as per these definitions. These definitions primarily focus on the functionality of trademarks and its visual perceptibility. However, the definition provided by the Trademark Law Treaty differs in this context. The treaty specifically excludes marks which are not consisting of visible signs, and excludes holograms, sound and olfactory marks. ${ }^{42}$

While defining the constituents of a trademark, Indian courts have primarily deliberated upon the open ended definition provided in the Trademarks Act, and have been forthcoming in including nonconventional characteristics, provided they bear the capability of being a mark. In the Zippo case $^{43}$ the Court, while discussing the registration of the shape-mark for its lighter by the plaintiff, observed that a pictorial representation of the mark would not only be considered as a registration for the device mark, but the shape mark as well, considering the subject matter of the registration. The rules also state that in case of a shape mark, five different views of the same, need to be present, and three, in case of a three dimensional mark. In case of any further confusion or ambiguity, the registrar may ask for a sample, or may cancel the same. ${ }^{44}$ The interpretation of the openness of the definition is done strictly on a case to case basis, depending on the subject matter of the registration. The shape and texture of the mark comprising of the trade dress of the product, was also considered as a trademark by

41 The Agreement on Trade-Related Aspects of Intellectual Property Rights, Art-15(1), Jan. 1, 1995.

42 Trademark Law Treaty, Art. 2(b), Oct. 27, 1994.

43Zippo Manufacturing Company v/ Anil Moolchandani (2006) CS(OS) 1355.

44 Rule- 26(3), (4) \& (6), The Trademarks Rules, 2017. 
the Delhi High Court, in the case of Ferrero Spa EAnr. vs Shri Maa Distribution. 45

The essential feature of a trademark is source identification, which refers to its ability to identify the origin of the product and judicial precedents also concede to this. The Bombay High Court recognized the essential function that the shape of a bottle was serving and observed:

The shape of the bottle which the plaintiff has adopted has no functional relationship with the nature of the product or the quality required of the container in which Vodka has to be sold. The shape is capricious, in the sense that it is novel and originated in the ingenuity and imagination of the plaintiff. Prima facie, a comparison of the shape of the bottle which has been adopted by the defendant, with the bottle of the plaintiff would show a striking similarity. ${ }^{46}$

In the Zippo case, ${ }^{47}$ the court referred to a previous case ${ }^{48}$ wherein the Court had a similar approach to the essential function of a trademark, the plaintiff's loaves of bread were of a size, shape, colour and condition of surface, that gave them a peculiar visible appearance, and they were recognized for the same. Thus, the defendant's manufacture and sale of similar loaves of bread was held to be infringing on the plaintiff's trademark.

\section{Graphical Representation and Procedural Requirements}

The three requirements that generally must and may be stipulated for a mark are that, they should be capable of fulfilling the function of being distinctive, which has two aspects in particular. Firstly, the mark should serve a distinctive function of enabling the consumers

${ }^{45}$ Ferrero Spa \&Anr. vs Shri Maa Distribution, (2010),CS(OS) 1763/2010, Delhi H.C.

${ }^{46}$ Gorbatschow Vodka KG v. John Distilleries Limited, (2010), SUIT NO.3046, Bom. H.C.

47Zippo Manufacturing Company v/ Anil Moolchandani (2006) CS(OS) 1355.

${ }^{48}$ George G. Fox Company v. Charles F. Hathaway \& Another, (1908) Mass Lexis 791. 
to distinguish the goods from those originating from other undertakings. The second aspect is that the mark should also be capable of individualizing the trademarked goods or services. ${ }^{49}$ The other two requirements are that it must be a sign, and that it must be capable of being represented graphically. These are the basic requirements for the protection of a trademark. Thus, if any nonconventional trademark fulfills such requirement, it can be registered, the same way as a conventional one. The term 'sign' or 'mark' for the trademark, should be interpreted in a broad sense and not in a restrictive one. It is this restrictive understanding of the term, which leads to the conclusion that the term 'sign' only appears to be limited by the fact that the relevant public must be able to perceive this as a signal, failing which the function of distinguishing the goods would not be fulfilled.

The requirement of graphical representation is the most crucial one in the context of non-conventional trademarks. Graphical representation of traditional trademarks is comparatively easy, as they can be easily represented on paper. The same is not the case with non-conventional marks. The representation of a smell mark, or a taste mark, or a particular color mark is quite difficult due to which the application of many non-conventional marks is rejected on the grounds of insufficient graphical representation. The rules for graphical representation of different non-conventional marks have been discussed in different cases. In the context of color marks, the graphical representation of the color is quintessential. The color used should be described in a clear and specific manner. Further, a description is also to be provided, as to how such a color is going to be used in the mark. It is however also accepted that the representation of color on paper might prove to be difficult which is the reason why a mere reference to a suitable code, may also be accepted.

In the Cadbury case, , $^{0}$ the application was for a rectangle, which is a purple block, applied to the whole visible surface, or being the

49 TOBIAS COHEN \& TONY HUYDECOPER , EUROPEAN TRADEMARK LAW-COMMUNITY TRADEMARK AND HARMONIZED NATIONAL TRADEMARK LAW, 75 ( 1st edition.2010).

50 Cadbury v. Nestle, (2017) E.W.C.A. Civ. 358, (United Kingdom). 
predominant color applied to the whole visible surface of the packaging of goods. The application was not for the color purple per se, but comprised the color swatch as a sample of the color, the Pantone shade, and the verbal description. ${ }^{51}$ It was held that "the use of the word 'predominant' opens the doors to a multitude of different visual forms as a result of its implied reference to other colors and visual material not displayed or described in the application, over which the purple color may predominate." 52 The Pantone shade can be deemed to be precise and adequate graphical representation, as it refers to a color system and an identified code, instead of a sample of color on a paper, which may fade with time. ${ }^{53}$

In the context of olfactory marks, graphical representation is quite a challenge, as the exact description of the odour is not achieved in many cases and thus the application is rejected because of this. One such example can be the Sieckmann case, ${ }^{54}$ wherein the application was rejected on the basis of lack of graphical representation. The application was for the pure chemical substance, methyl cinnamate, whose odour was described to be akin to a balsamic fruit with a hint of cinnamon. The chemical formula was provided along with a bottle of the scent as well, for the purposes of consideration. The graphical representation was considered to be inadequate because the public would not be able to comprehend the chemical formula. It was also observed that the scent was volatile, which led to the conclusion that depositing it in a bottle is not the adequate solution. The application was considered to be not intelligible enough for the public to understand, as it lacked clarity. ${ }^{55}$ A seven-step test is followed in the E.U for an adequate representation, the representation should be clear, precise, self-contained, easily

51Societe Des Produits Nestle SA v. Cadbury UK Ltd, (2013) E.W.C.A Civ 1174(CA), (United Kingdom).

52Ibid.

${ }^{53}$ LibertelGroep BV v. Benelux-Merkenbureau, (2003) E.C.R I-3793, (Europe).

54 Ralf Sieckmann v. Deutsches Patent and Markenamt, (2002) A.1.1E.R(D) 185.

55 Ralf Sieckmann v. Deutsches Patent and Markenamt, (2002) A.1.1E.R(D) 185. 
accessible, durable, intelligible and objective. In the U.S, a detailed description which efficiently describes the scent is sufficient. ${ }^{66}$ The first such registration was granted in the Re Clarks case. ${ }^{57}$

In the case of sound marks, the representation of the sound is not considered to be adequate when described in words. Musical notes are the most commonly accepted form of sound marks. The application for registration of Tarzan's yell as a mark, was rejected on grounds of a lack of graphical representation. In the application, the yell was described in words along with a spectrogram of the yell, consisting of the three-dimensional depiction of frequency. ${ }^{58}$ The examiners of Office of Harmonization in the Internal Market, (presently known as the European Union Intellectual Property Office), refused registration on the grounds that the sonogram was not self-contained, clear or intelligible, thereby not meeting the criteria of graphical representation. The description of the mark in written language and in onomatopoeia was rejected and the method of representation of sound mark in musical notes by the stave and clef method was approved. 59

India has recognized several sound marks, Yahoo yodel being the first and many followed such as those of Britannia, ICICI Bank etc. The acceptance of Yahoo yodel as a sound mark has opened new doors for the recognition and protection of many more similar sound marks. What still remained unclear was the proper mode of graphical representation for sound marks considering that the judgment in the Yahoo yodel $\mathrm{case}^{60}{ }^{6}$ was silent about the same. It may have been a landmark in the field of trademark law, but it did not shed any light on the graphical representation of the mark. This serves to be the biggest obstacle in the registration of sound marks. This was later discussed by the Draft Manual. According to the Draft Trademark Manual of India, 2015, the representation ought to be clear, self-contained, intelligible, precise, objective and

\footnotetext{
${ }^{56}$ Supra note 15.

57 Re Celia Clarks, 17 USPQ 2d 1238(TTAB 1990)

58 Edgar Rice Burroughs Inc. v. OHIM, Case R 708/2006-4.

59 Shield Mark BV v. Joost Kist h.o.d.nMemex, (2004), Case-C-283/01, R.P.C 17.

60 Yahoo!, Inc. v. Akash Arora \& Anr.78 (1999) D.L.T. 285
} 
durable. Two conditions must be satisfied- the application should state that the mark is a sound mark, and the graphic representation requirements should be met by a musical stave divided into measures and showing, in particular, a clef. ${ }^{61}$ Additionally, it has excluded the following categories from registration, namely, simple musical pieces comprising of 1 or 2 notes, songs commonly used as chimes, well known popular music, children's nursery rhymes and music associated with a particular region or country. Also, an easier way of graphical representation for sound marks was proposed in the form of mp3 files. ${ }^{62}$ It is needless to say that an electronic version of the sound mark stored in an mp3 file would be the best method of graphical representation so far, as it eliminates any sort of confusion that may have arisen on account of a written description or a musical notation. Also, such a representation can be easily perceived and understood.

\section{Conclusion}

These are the general rules that are to be followed over the registration of nonconventional marks, and if the conditions are satisfied, there is no reason why a nonconventional trademark should not be registered. Thus, we can see that the registration of such marks is comparatively easier in the U.S as compared to E.U or India. The requirement of graphical representation is not there in the U.S and thus, the application process is made much easier - a mere detailed description of the mark would suffice. In the E.U the requirement of a clear, precise, intelligible, objective graphical requirement makes such registration much more stringent. As is reflected in numerous cases, registration of marks was denied not on the evaluation of the effectiveness of the mark, but on the grounds that it lacked sufficient graphical representation.

Concluding from the above-mentioned cases and the draft manual, it can be said that India, to a certain extent, has imitated the E.U's requirements in this context. This makes the registration much more stringent when compared to the U.S, wherein a detailed

61 Draft Manual for Trade Mark Practice and Procedure of India, Ministry of Trade and Commerce of India (2015).

62 Rule- 26(5), The Trademarks Rules, 2017. 
description is by itself adequate. Such an approach is imperative to the development of the country's trademark law, as the law should be inclusive of an essential component of its subject matter, which is gaining recognition rapidly across the world.

The new rules strive to make the process of registration easier, while also encouraging the registration of non conventional marks by providing certain instructions for their graphical representation. However, there still remain numerous lacunae. Ambiguity still prevails in many aspects, such as, the rules relating to the registration of taste or olfactory marks. Despite the progress made so far in relation to the expansion of trademark protection, the openness of the definition of a trademark needs to be accepted and practiced in real life, beyond statutory literature. 